\title{
Avaliação da expansão de um solo do município de Paulista-PE melhorado com cal
}

\author{
Expansion evaluation of a soil of the municipality of \\ Paulista-PE improved with lime
}

Silvio Romero de Melo Ferreira ${ }^{1}$, Sergio Carvalho de Paiva ${ }^{2}$ Joanderson James Oliveira Morais ${ }^{1}$, Rafael Bazilio Viana ${ }^{2}$

\author{
${ }^{1}$ Universidade Federal de Pernambuco, Av. Acadêmico Hélio Ramos s/n, CEP 50740-530, Recife, PE, Brasil, \\ e-mail: joandersonjames@gmail.com; sr.mf@hotmail.com \\ ${ }^{2}$ Universidade Católica de Pernambuco, Rua do Príncipe, 526, Boa Vista, CEP 50050-900, Recife, PE, Brasil, \\ e-mail: spaiva@unicap.br, bazilioviana@gmail.com
}

\section{RESUMO}

A variação de volume dos solos expansivos devido à mudança de umidade causa danos socioeconômicos e ambientais para as obras de engenharia geotécnica. Dois requisitos básicos são necessários para que um solo apresente expansividade, um intrínseco e outro extrínseco. O primeiro está relacionado com a composição mineralógica, textura e estrutura do solo e o segundo com o comportamento do clima, o volume e o movimento das águas subterrâneas, a vegetação e a ocupação antrópica. A adição da cal ao solo expansivo melhora as propriedades geotécnicas da mistura. A cal tem interações físico-químicas com o solo expansivo capazes de estabilizar a variação de volume. Várias edificações em construção no Estado de Pernambuco encontram-se localizadas em áreas de ocorrência de solos expansivos. O efeito do tratamento da cal nas propriedades do solo expansivo de Paulista foi investigado, comparando-se o comportamento do solo natural e do solo misturado com a cal nas proporções, em peso, de 3\%, 5\% e 7\%. Foram realizados ensaios de caracterização física, química e mineralógia (por termogravimetria (TG) e difratometria de raio-X), expansão livre e tensão de expansão. O solo natural apresentou alta expansividade. A tensão de expansão foi influenciada pela trajetória de tensão seguida durante o ensaio. A adição de cal ao solo causou uma agregação ou floculação das partículas e uma redução no índice de plasticidade. A adição de $5 \%$ de cal hidratada ao solo de Paulista estabilizou quanto a expansão livre e tensão de expansão.

Palavras-chave: Solo Expansivo, Estabilização, Cal.

\begin{abstract}
The volume variation of the expansive soils due to the change of water content causes socioeconomic and environmental damage to geotechnical engineering works. Two basic requirements are needed for a soil to exhibit expansiveness, one intrinsic and the other extrinsic. The first is related to the soil mineralogical composition, texture and structure and the second with the behavior of climate, the volume and the movement of groundwater, the vegetation and the anthropic occupation. The addition of lime to the expansive soil improves the geotechnical properties of the mixture. The lime has physical-chemical interactions with the expansive soil capable of stabilizing the volume variation. Several buildings under construction in the State of Pernambuco are located in areas of occurrence of expansive soils. The effect of lime treatment on the properties of Paulista expansive soil was investigated, comparing the behavior of natural soil and soil mixed with lime in the proportions of $3 \%, 5 \%$, and $7 \%$ by weight. Physical, chemical and mineralogical characterization tests (by thermogravimetry (TG) and X-ray diffractometry), free expansion and expansion stress were carried out. The natural soil presented high expansiveness. The determination of the expansion voltage was influenced by the voltage trajectory followed during the test. The addition of lime to the soil caused an aggregation or flocculation of the particles and a reduction in the plasticity index. The addition of $5 \%$ of hydrated lime to the soil of Paulista stabilized in relation to the free expansion and the expansion tension.
\end{abstract}

Keywords: Expansive soil, Stabilization, Lime. 


\section{INTRODUÇÃO}

A variação volumétrica por expansão ou contração do solo devido ao ganho ou perda de água pode causar tensões indesejáveis nas estruturas em obras de engenharia. A mudança de volume depende do tipo de mineral argílico existente na fração argila, visto que nem todos os filossilicatos apresentam alterações volumétricas quando ocorre alteração de umidade. A instabilidade é relevante nas vermiculitas e nas montmorilonitas. As alterações do volume, devido à variação da tensão externa ou da sucção, são orientadas pela presença da água nas bordas das partículas dos argilominerais. Há outros fatores relacionados ao solo. como distribuição das partículas de argila, porosidade, orientação mineralógica, perfil estratigráfico e espessura do solo, que atuam de modo secundário no seu potencial expansivo [1,2].

A ocorrência de instabilidade volumétrica (contração, expansão ou colapso) de solos por causa da mudança no teor de água é complexa e motivada por vários fatores, dentre os quais o tipo de solo, o clima e os estados de tensão [1,2]. Diversos são os tipos de solos expansivos; entre eles destacam-se os solos formados a partir de rochas ígneas, onde os feldspatos e piroxênios, se decompõem para formar montmorilonita e minerais secundários e solos originados de rochas sedimentares com constituinte argilomineral montmorilonita, [1].

No Brasil, os solos expansivos podem ser encontrados em várias regiões do país. Entre as principais formações expansivas conhecidas estão as bacias sedimentares do Recôncavo Baiano, do Paraná e do Rio Grande do Sul [3]. Em Pernambuco, Ferreira [4] identificou e estudou solos expansivos nos municípios de Afrânio, Petrolina, Cedro, Cabrobó, Salgueiro, Floresta, Serra Talhada, Petrolândia, Inajá, Ibimirim, Carnaíba, Nova Cruz, Paulista, Olinda, Recife e Cabo.

A aplicação de técnicas de estabilização de solos para proporcionar a alteração de suas características geotécnicas tem-se revelado cada vez mais importante na resolução de problemas, viabilizando, assim, obras de engenharia. A estabilização dos solos pode ser obtida pelo uso de diferentes técnicas. A opção por uma ou outra técnica de estabilização é influenciada por uma série de fatores, dentre os quais se destacam os custos totais da obra, as características dos materiais, as propriedades que devem ser corrigidas, além da própria finalidade da obra.

Um dos tratamentos que vem sendo aplicado no melhoramento dos solos expansivos, e que é base deste estudo, é a adição de cal. A cal é um aglomerante aéreo, resultante da calcinação dos calcários ou dolomitos através de decomposição térmica, e posterior hidratação formando o hidróxido de cálcio $\left(\mathrm{Ca}(\mathrm{OH})_{2}\right)$ que tem diversas utilidades em várias atividades humanas. Ao ser adicionado ao solo, o hidróxido de cálcio modifica imediatamente o pH deste solo; o cálcio evita a penetração da água nos vazios dos argilominerais neutralizando suas cargas negativas e favorecendo a floculação e a troca catiônica. Com o tempo, há reações de cimentação, finalizadas com a reação com o $\mathrm{CO}_{2}$ do ar formando silicatos, aluminatos e aluminosilicatos de cálcio hidratado, com propriedades cimentantes [5].

A expansão e a contração de um solo são normalmente reduzidas quando o solo é tratado com cal. A cal tende, pela floculação das partículas, a reduzir as mudanças de volume apresentadas pelos solos. A diminuição da expansão e a contração é atribuída à redução da afinidade por água das argilas saturadas pelo íon cálcio e pela formação de uma matriz cimentante.

Há diversos projetos de infraestrutura que serão implantados no país, em especial no Nordeste, e vários deles serão executados em solos expansivos. O presente artigo tem por objetivo analisar o efeito da interação da cal hidratada com solo expansivo no município de Paulista-PE, utilizando mistura do solo, em peso, com, 3\%, 5\%, 7\% de cal.

\section{MATERIAIS E MÉTODOS}

O comportamento do solo expansivo de Paulista - PE e das misturas solo-cal foi analisado em amostras indeformadas e compactadas, respectivamente. Amostras deformadas foram coletadas nas profundidades de 0 a $0,2 \mathrm{~m}, 0,2$ a $0,4 \mathrm{~m}, 0,6$ a $0,8 \mathrm{~m}$ e uma amostra indeformada (tipo bloco) foi coletada na profundidade de 0,8 a 1,1 m. Ensaios em laboratório foram realizados na cal hidratada, no solo e nas misturas solo-cal. $\mathrm{O}$ ensaio de compactação no solo e nas misturas solo-cal foi realizado na amostra do solo coletada da profundidade de 0,8 a $1,1 \mathrm{~m}$.

Parte da costa leste do litoral pernambucano está inserido na sedimentação farenozóica da Bacia do Paraíba, onde ocorrem cinco formações geológicas que subdividem as duas sub-bacias (Alhandra e Olinda). São encontradas nessa bacia as formações Beberibe, Itamaracá, Gramame, Maria Farinha e Barreiras (Figura 1). Segundo Barbosa et al. [6], a formação Beberibe é composta por arenitos continentais médios a grossos variando até arenitos conglomeráticos de ambientes flúvio lacustres. Acima da Formação Beberibe encontrase a formação Itamaracá composta por depósitos costeiros de estuários e lagoas, contendo fósseis de ambiente marinho salobro, além de arenitos carbonáticos, folhelhos e carbonatos com siliciclastos ricamente fossilíferos. A Formação Gramame está representada por calcários e margas depositados em uma plataforma carbonática de 100 a 150 metros de espessura. O solo expansivo de Paulista-PE é resultado do intemperismo 
físico e químico de argilitos e calcário da Formação Maria Farinha. Está situado na Estação de Tratamento de Esgoto do Janga (ETE-Janga). O clima é tropical úmido, com estação chuvosa no inverno. Há, normalmente, dois períodos de chuvas e estiagem, com período úmido curto e período seco longo.

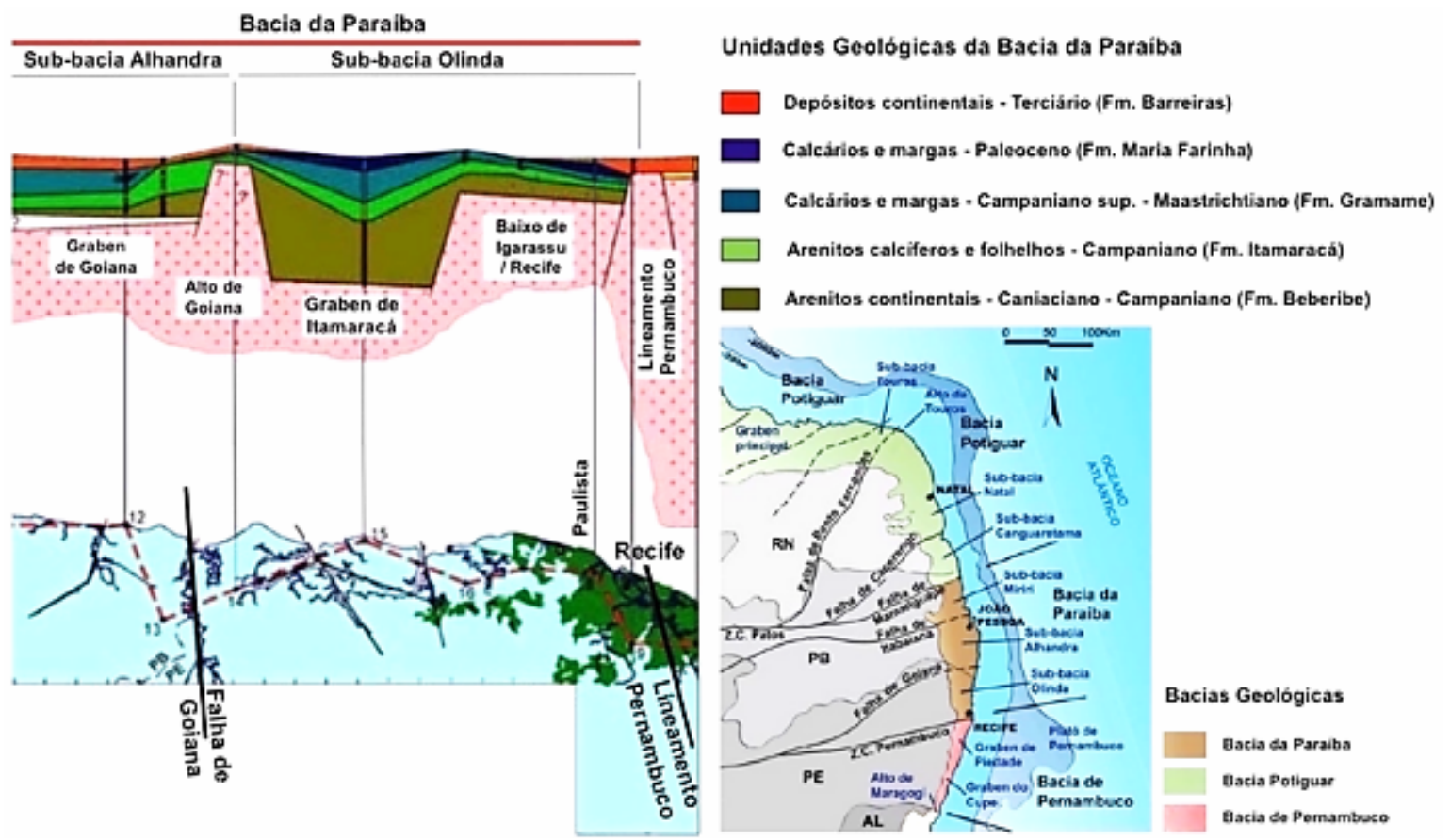

Figura 1: Recorte do perfil geológico ao longo da linha da costa pernambucana da Bacia do Paraíba e localização das Bacias de Pernambuco, Paraíba e Potiguar (Adaptado de [7]).

A caracterização da cal hidratada foi realizada segundo a norma da ABNT [8]. A determinação da retenção de água foi realizada de acordo com a ABNT [9] e a determinação da finura pela ABNT [10]. As determinações de umidade; perda ao fogo; óxido de silício; óxido férrico; óxido de cálcio; óxido de magnésio e massa específica foram realizadas segundo a ABNT [11]. As determinações foram realizadas em tréplica.

As porcentagens de cal a serem adicionadas ao solo para a estabilização quanto a expansão foram inicialmente definidas a partir do critério de Eades e Grim [12]. O critério define que o menor teor de cal que estabiliza a mistura é aquele que adicionado ao solo eleva o $\mathrm{pH}$ da mistura solo-cal a 12,42, após uma hora do início da mistura dos materiais. As misturas (solo-cal) nas porcentagens de 3\%, 5\% e 7\%, em peso, foram homogeneizadas e os ensaios de caracterização física, química, mineralógica, microscopia eletrônica de varredura (MEV) expansão livre e tensão de expansão foram realizados após uma hora. Os métodos utilizados para o solo foram os mesmos para a mistura solo-cal.

Os ensaios de caracterização realizados seguiram as seguintes metodologias: preparação para ensaios de caracterização, executado segundo as prescrições da ABNT [13] e ABNT [14] e ensaios de caracterização; determinação do limite de liquidez, conforme ABNT [15]; determinação do limite de plasticidade, conforme ABNT [16]; determinação da massa específica, conforme ABNT [17], análise granulométrica, conforme ABNT [18]. A sucção do solo natural foi avalidada pelo método do papel filtro, conforme [19].

A análise química do solo e das misturas solo-cal foi realizada conforme a metodologia proposta por [20] no Manual de Métodos de Análise de Solos da Embrapa e os resultados foram calculados, de acordo com o [21] utilizando o sistema de classificação de solos da Embrapa: soma de bases (S); capacidade de troca catiônica (CTC ou T); saturação por bases (V).

A espectrometria de fluorescência de raios-X (FRX) foi utilizada para a avaliação quantitativa da composição química do solo. Foram determinados os teores dos dez óxidos de maior abundância: $\mathrm{SiO}_{2}, \mathrm{Al}_{2} \mathrm{O}_{3}, \mathrm{Fe}_{2} \mathrm{O}_{3}$, $\mathrm{CaO}, \mathrm{MnO}, \mathrm{MgO}, \mathrm{Na}_{2} \mathrm{O}, \mathrm{K}_{2} \mathrm{O}, \mathrm{TiO}_{2}$ e $\mathrm{P}_{2} \mathrm{O}_{5}$. Uma amostra de cada solo e das misturas solo-cal foram colocadas em estufa para secar a $110{ }^{\circ} \mathrm{C}$ e levadas a uma mufla, a $1000{ }^{\circ} \mathrm{C}$, por duas horas, para a determinação de perda ao fogo. Foram preparadas pérolas fundidas usando tetraborato de lítio como fundente, que foram analisadas em espectrômetro de fluorescência de raios X, Rigaku modelo RIX 3000, equipado com tubo de Rh, pelo método de curvas de calibração, que foram construídas com materiais de referências internacionais.

A análise mineralógica foi feita por termogravimetria (TG), termogravimetria derivada (DTG) e difratometria de raio X. Foi utilizado o equipamento modelo NETZSCH STA 409PC com atmosfera de Nitrogênio 5,0 analítico e taxa de aquecimento de $10^{\circ} \mathrm{C} /$ minuto, até uma temperatura máxima de $1000{ }^{\circ} \mathrm{C}$. Os 
resultados foram analisados com auxílio do programa NETZSCH Proteus - Termal Analysis Version 4.2.1. Também foi realizada a difração de raio-X na argila total $(<0,002 \mathrm{~mm})$. Para tanto foram preparadas três lâminas: duas saturadas com potássio, uma das quais foi levada ao raio-X à temperatura ambiente $\left(25^{\circ} \mathrm{C}\right)$ e a outra aquecida previamente a $550{ }^{\circ} \mathrm{C}$ por duas horas; a terceira lâmina, foi saturada com magnésio e impregnada com glicerol a 10\%. As lâminas foram preparadas com orientação paralela, de acordo com [22]. Os dados foram coletados empregando-se um difratômetro Shimadzu XRD-6000 com radiação CuKT, tensão de $40 \mathrm{KV}$, corrente de $30 \mathrm{~mA}$, tamanho do passo de 0,020 2U e tempo por passo de 1,000s, com velocidade de varredura de $2^{\circ}(2 \mathrm{U}) / \mathrm{min}$, com ângulo $2 \mathrm{U}$ percorrido de 2 a $42^{\circ}$.

A MEV foi utilizada para analisar a microestrutura. Após secagem do solo seco ao ar foram moldados três corpos de prova, de formato prismático, com base de $9,8 \mathrm{~mm}$ e altura de $8 \mathrm{~mm}$, tendo-se o cuidado para que nenhum instrumento cortante ou pontiagudo tocasse na superfície de observação, utilizando a técnica descrita por [19]. A metalização foi realizada com ouro por meio de evaporação através de uma campânula de vácuo do tipo Fine Coat, Ion Sputter JfC-1100 da marca JEOL. Foi utilizado o equipamento JSM T200 Scanning Microscope de marca JOEL, com máquina fotográfica acoplada, e poder de resolução que permitiu aumentos de 40.000 vezes.

Os ensaios de expansão "livre" foram realizados em células edométricas convencionais com amostras indeformadas do solo e nas misturas solo-cal em amostras compactadas na umidade ótima e peso específico aparente seco máximo, talhadas em anéis de aço inoxidável de altura 20,00 mm e diâmetro de 71,3 mm, e submetidas a pequenas tensões seguindo os procedimentos da ABNT [23].

A tensão de expansão no solo foi determinada por três métodos: 1 - carregamento após expansão com diferentes tensões verticais de consolidação; 2 - expansão e colapso sob tensão; e 3 - volume constante em amostras indeformadas, conforme descreve Ferreira e Ferreira [24]. A expansão livre e a tensão de expansão determinadas pelo método de volume constante nas misturas solo-cal foram avaliadas em amostras compactadas na umidade ótima e peso específico aparente seco máximo. Os valores dos potenciais de expansão (SP), obtidos por meio dos ensaios edométricos simples, foram calculados pela Equação 1.

$\mathrm{SP}=\Delta \mathrm{h} \times 100 / \mathrm{hi}$

Onde: SP é o pontencial de expansão, $\Delta$ h é a variação da altura do corpo de prova devido à inundação e hi é a altura do corpo de prova antes da inundação.

\section{RESULTADOS}

Serão analisadas inicialmente as caracterizações física e química da cal e posteriomente a caracterização fisica, química, mineralógica, microestrutural e a expansividade do solo e da mistura solo-cal.

\subsection{Caracterização da Cal}

A Tabela 1 apresenta os resultados da caracterização física e química. Verifica-se que todos os parâmetros analisados apresentaram resultados compatíveis com uma cal de ótima qualidade (CHI), segundo a ABNT [8].

Tabela 1. Resultados das análises físicas e químicas na cal

\begin{tabular}{lll}
\hline DETERMINAÇÕES & UNIDADE & $\begin{array}{l}\text { VALOR } \\
\text { (DESVIO PADRÃO) }\end{array}$ \\
\hline Umidade & $\%$ & $1,31(0,45)$ \\
Perda ao fogo & $\%$ & $24,23(0,50)$ \\
Oxido de ferro $\left(\mathrm{Fe}_{2} \mathrm{O}_{3}\right)$ & $\%$ & $0,22(0,09)$ \\
Oxido de cálcio total $\left(\mathrm{CaO}_{\mathrm{T}}\right)$ & $\%$ & $66,93(0,18)$ \\
Oxido de cálcio disponível $\left(\mathrm{CaO}_{\mathrm{D}}\right)$ & $\%$ & $58,49(0,51)$ \\
Anidrido Carbônico $\left(\mathrm{CO}_{2}\right)$ & $\%$ & $4,09(0,09)$ \\
Massa específica & $\mathrm{g} / \mathrm{mL}$ & $0,45(0,05)$ \\
Finura Peneira 30 - 0,600 mm & $\%$ & $0,10(0,02)$ \\
$\quad$ Peneira $200-0,075 \mathrm{~mm}$ & $\%$ & $0,13(0,03)$ \\
Retenção de água & $\%$ & $87,00(0,52)$ \\
\hline
\end{tabular}

\subsection{Caracterização Física do Solo e das Misturas Solo-Cal}

O solo expansivo de Paulista apresentou de $16 \%$ a $31 \%$ areia, $17 \%$ a $37 \%$ de silte e $41 \%$ a $51 \%$ de argila e a relação silte/argila diminuía com a profundidade. Tinha plasticidade alta (IP variou de $24 \%$ a $34 \%$ ) e a 
atividade normal (variou de 55 a 73\%), conforme Tabela 2. O peso específico real dos grãos foi de 26,14 $\mathrm{kN} / \mathrm{m}^{3}$. O solo possuía argila de alta compressibilidade $(\mathrm{CH})$ em acordo com a classificação Unificada dos Solos.

A adição de cal ao solo de Paulista causou um pequeno acréscimo da fração argila e praticamente não modificou a fração silte e areia fina. A forma da curva de distribuição de frequência de partículas do solo era unimodal e passou a ser bimodal com a adição da cal, tendo dois picos; o primeiro ocorria entre 0,005 mm e $0,007 \mathrm{~mm}$ e o segundo entre $0,05 \mathrm{~mm}$ e $0,07 \mathrm{~mm}$ (Figura 2a). A adição da cal ao solo causou diminuição nos valores do limite de liquidez e acréscimo no limite de plalticidade, ocasionando redução do índice de plasticidade, concordando com Thomé [25], Al-Rawas e Goosen [26] e Klinsky et al. [27] (Figuras 2b). Brandl [28] considerou que as rápidas mudanças nos valores dos limites de Atterberg com adição de cal devem-se às transformações estruturais e floculação do material. Houve pequena variação da umidade ótima com o acréscimo do teor de cal até $5 \%$ e o peso específico seco máximo cresceu ou ficou praticamente constante com o aumento da teor de cal (Tabela 2).

Tabela 2: Granulometria, consistência e compactação do solo e da mistura solo-cal

\begin{tabular}{l|l|l|l|l|l|c|c}
\hline \multirow{2}{*}{ CARACTERIZAÇÃo } & \multicolumn{5}{|c|}{ SOLO PROFUNDIDADE $\mathrm{m}$} & \multicolumn{3}{c}{ MISTURA SOLO-CAL * } \\
\cline { 2 - 9 } & $0,0-0,2$ & $0,2-0,4$ & $0,4-0,6$ & $0,8-1,1$ & $\begin{array}{l}\text { SOLO + } \\
\text { 3\% CAL }\end{array}$ & $\begin{array}{l}\text { SOLO } \\
\text { 5\% CAL }\end{array}$ & $\begin{array}{l}\text { SOLO + } \\
7 \% \text { CAL }\end{array}$ \\
\hline Pedregulho (\%) & 01 & 01 & 01 & 00 & 0 & 0 & 0 \\
\hline Areia (\%) & 28 & 21 & 21 & 16 & 18 & 16 & 16 \\
\hline Silte (\%) & 27 & 27 & 32 & 37 & 32 & 27 & 28 \\
\hline Argila (\%) & 44 & 51 & 46 & 47 & 50 & 57 & 56 \\
\hline WL (\%) & 52 & 61 & 56 & 61 & 55 & 54 & 58 \\
\hline WP (\%) & 28 & 27 & 27 & 31 & 36 & 42 & 41 \\
\hline IP (\%) & 24 & 34 & 29 & 30 & 18 & 12 & 17 \\
\hline $\begin{array}{l}\text { Índice de Atividade } \\
(\%)\end{array}$ & 55 & 66 & 73 & 63 & 36 & 21 & 30 \\
\hline Umidade ótima (\%) & - & - & - & 21,00 & 22,88 & 20,78 & 23,78 \\
\hline pdmax (kN/m $\left.{ }^{3}\right)$ & - & - & - & 15,00 & 15,59 & 15,65 & 15,65 \\
\hline
\end{tabular}

WL - Limite de Liquidez, WP - Limite de Plasticidade, IP - Índice de Plasticidade, Pdmax - Peso específico aparente seco máximo $\left(\mathrm{kN} / \mathrm{m}^{3}\right) *$ solo da profundidade de 0,8 a $1,1 \mathrm{~m}$ misturado com a cal.
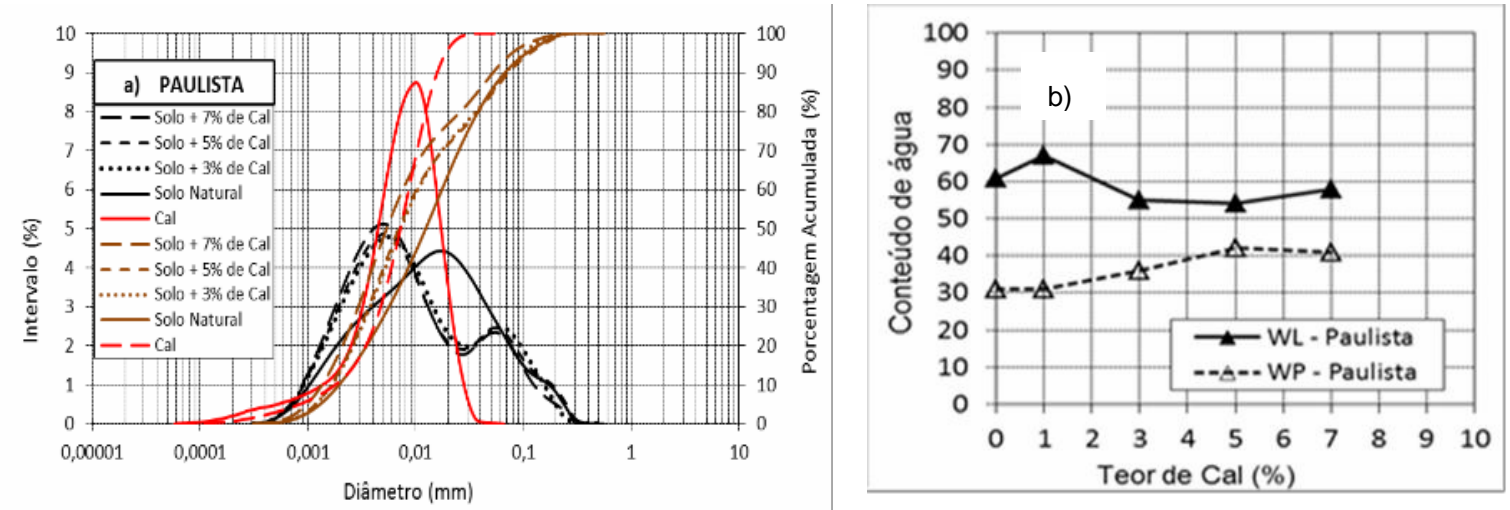

Figura 2: a) Distribuição dos tamanhos das partículas do solo, da cal e das misturas solo-cal, b) variação dos limites de liquidez e plasticidade com o teor de cal.

A Figura 3 mostra vários critérios comumente utilizados no mundo para determinar o potencial de expansão. O potencial de expansão da argila de Paulista foi médio a alto, pelos critérios de Skempton [29], Van Der Merve [30] e Seed et al. [31] e alto pelos critérios de Daksanamurthy e Raman [32] e Yilmaz [33].

\subsection{Caracterização Química do Solo e das Misturas Solo-cal}

São apresentados os resultados da análise química na Tabela 3. No solo natural o pH é ácido $(<7)$ e a capacidade de troca de cátions é alta (CTC $>27 \mathrm{cmol} / \mathrm{kg}$ ). A saturação de base é alta (valor V > 50\%). A 
percentagem de sódio é baixa até a profundidade de 0,80 m e apresenta um caráter sódico $(100 \mathrm{Na} / \mathrm{T})$ superior a 15. A capacidade de troca catiônica de um solo pode indicar quanto o solo é evoluido, tipo de minerais argílicos e expansividade. Buol et al. [34] consideram os solos com CTC maiores que $20 \mathrm{cmol}_{\mathrm{c}} / \mathrm{kg}$ podem apresentar altos teores de montmorilonita, sendo assim, um solo expansivo. O óxido de silício prevaleceu sobre o óxido de alumínio e sobre o óxido de ferro (Tabela 4).
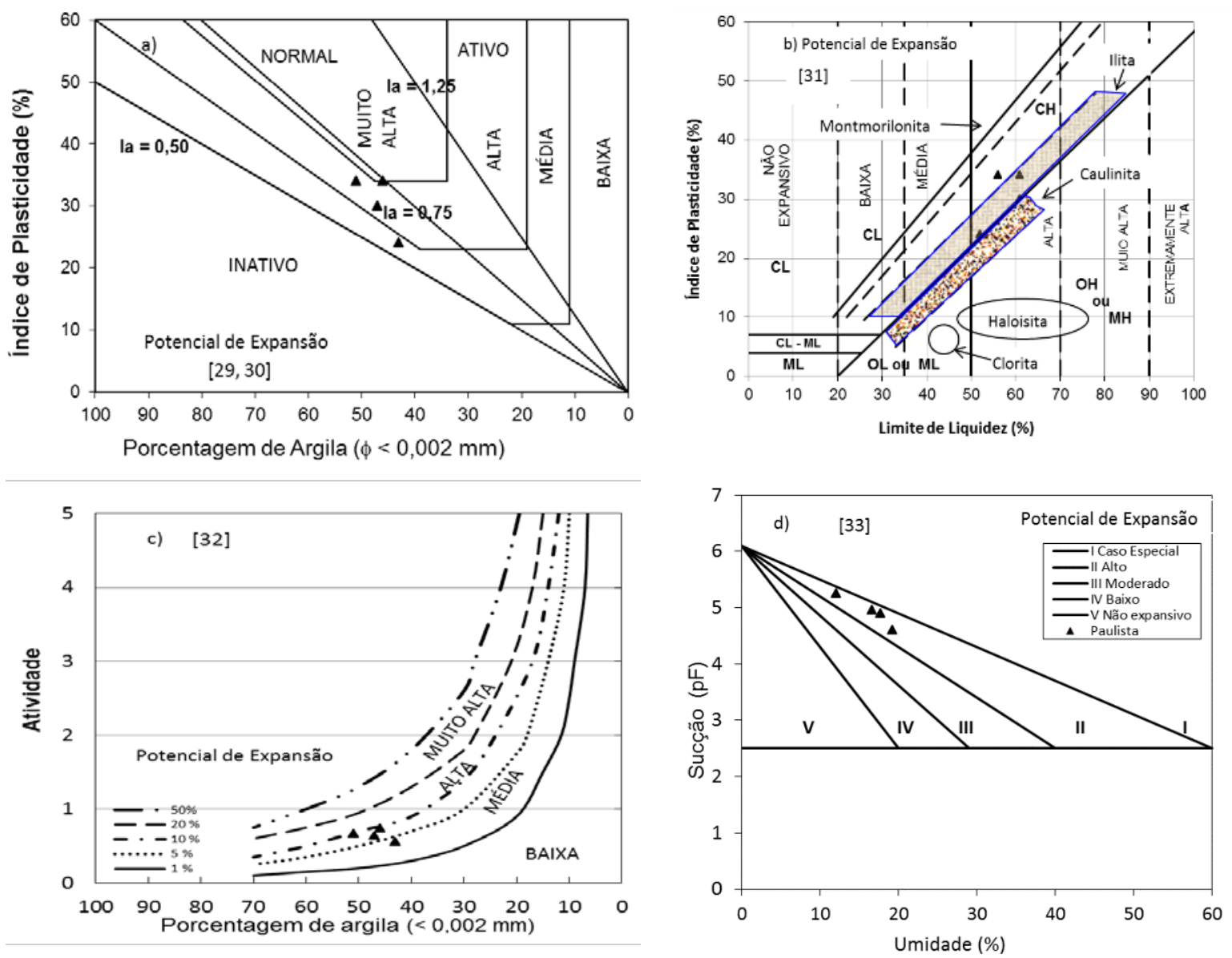

Figura 3: Critérios comumente utilizados no mundo para determinar o potencial de expansão: a) SKEMPON [29] Van Der Merve [30] b) DAKSANAMURTHY e RAMAN [31], c) SEED et al [32], e d) YILMAZ [33].

Tabela 3: Caracterização Química do solo e das misturas solo-cal

\begin{tabular}{|c|c|c|c|c|c|c|c|c|c|c|c|}
\hline \multirow{2}{*}{$\begin{array}{l}\text { Solo } \\
\text { Profundidade } \\
\text { (m) }\end{array}$} & \multirow{2}{*}{$\begin{array}{l}\mathrm{pH} \\
\mathrm{H}_{2} \mathrm{O}\end{array}$} & $\mathrm{Na}^{+}$ & $\mathrm{K}^{+}$ & $\mathrm{Ca}^{2+}$ & $\mathrm{Mg}^{+2}$ & $\mathrm{Al}^{3+}$ & $\mathrm{H}^{+}$ & S & CTC & $\mathrm{V}$ & $100 \mathrm{Na}^{+} / \mathrm{T}$ \\
\hline & & \multicolumn{8}{|c|}{ - ---------------------- $\mathrm{cmol}_{\mathrm{C}} / \mathrm{kg}$} & \multicolumn{2}{|c|}{----------- \% --------. } \\
\hline $0,0-0,2$ & 4,91 & 1,34 & 27,73 & 2,10 & 3,40 & 7,40 & 8,90 & 34,57 & 50,87 & 67,98 & 2,63 \\
\hline $0,2-0,4$ & 4,94 & 0,22 & 30,17 & 2,40 & 26,00 & 12,00 & 9,80 & 58,79 & 80,59 & 72,95 & 0,27 \\
\hline $0,4-0,6$ & 4,77 & 4,22 & 19,23 & 1,00 & 23,80 & 12,50 & 9,30 & 48,25 & 70,05 & 68,88 & 6,02 \\
\hline $0,8-1,1$ & 4,93 & 14,6 & 5,01 & 2,30 & 4,40 & 10,10 & 9,80 & 26,30 & 46,30 & 56,80 & 31,50 \\
\hline \multicolumn{12}{|c|}{ Mistura solo-cal } \\
\hline Solo*+3\% cal & 11,47 & 48,1 & 11,1 & 35,6 & 2,10 & 0 & 0 & 96,90 & 96,90 & 100 & 49,50 \\
\hline Solo*+5\% cal & 12,43 & 32,9 & 7,7 & 55,8 & 1,10 & 0 & 0 & 97,60 & 97,60 & 100 & 33,70 \\
\hline Solo*+7\% cal & 12,50 & 30,3 & 7,7 & 74,4 & 5,60 & 0 & 0 & 118,0 & 118,10 & 100 & 25,40 \\
\hline
\end{tabular}

Legenda: $\mathrm{S}=\mathrm{Na}^{+}+\mathrm{K}^{+}+\mathrm{Ca}^{2+}+\mathrm{Mg}^{2+} ; \mathrm{CTC}=\mathrm{Na}^{+}+\mathrm{K}^{+}+\mathrm{Ca}^{2+}+\mathrm{Mg}^{2+}+\mathrm{Al}^{3+}+\mathrm{H}^{+} ; V=100 \frac{S}{T}$;

* A mistura foi realizada com a amostra do solo coletado entre as profundidades de $0,80 \mathrm{~m}$ a $1,10 \mathrm{~m}$. 
O solo ácido torna-se alcalino com o acréscimo de cal. Tanto o solo natural quanto as misturas são classificadas como eutróficas (valor $\mathrm{V}>50 \%$ ) com uma alta capacidade de troca de cátions, e caráter sádico. Os óxidos desse solo após a adição da cal apresentaram uma redução nos óxidos de silício, ferro, potássio e titânio e um aumento de 26 vezes na quantidade de cálcio, com o percentual de 7\% de cal. Os valores do óxido de cálcio, determinados segundo as recomendações da norma ABNT [8] (Tabela 1), e pela técnica analítica de espectrometria de fluorescência de raio-X (Tabela 4), são próximos.

Tabela 4: Valores das porcentagens de óxidos e perda ao fogo no solo e na cal e nas mistruras solo-cal

\begin{tabular}{l|l|l|l|l|l|l|l|l|l|l|l|l}
\hline MATERIAL & \multicolumn{10}{c}{ ÓXIDOS (\%) } \\
\hline & $\mathrm{SiO}_{2}$ & $\mathrm{Al}_{2} \mathrm{O}_{3}$ & $\mathrm{Fe}_{2} \mathrm{O}_{3} \mathrm{t}$ & $\mathrm{MgO}$ & $\mathrm{MnO}$ & $\mathrm{CaO}$ & $\mathrm{Na}_{2} \mathrm{O}$ & $\mathrm{K}_{2} \mathrm{O}$ & $\mathrm{TiO}_{2}$ & $\mathrm{P}_{2} \mathrm{O}_{5}$ & $\mathrm{PF}$ & Total \\
\cline { 2 - 13 } Solo* & 65,54 & 15,27 & 5,05 & 0,68 & 0,00 & 0,14 & 0,00 & 1,77 & 0,87 & 0,02 & 11,88 & 97,48 \\
\hline Cal & 0,00 & 1,50 & 0,00 & 1,93 & 0,00 & 66,42 & 0,00 & 0,12 & 0,06 & 0,01 & 27,44 & 101,22 \\
\hline $\begin{array}{l}\text { Solo } \\
+3 \% \text { de Cal }\end{array}$ & 63,97 & 14,92 & 4,86 & 0,72 & 0,00 & 1,75 & 0,00 & 1,73 & 0,84 & 0,02 & 12,37 & 101,18 \\
\hline $\begin{array}{l}\text { Solo } \\
+5 \% \text { de Cal }\end{array}$ & 62,94 & 14,64 & 4,72 & 0,72 & 0,00 & 2,80 & 0,00 & 1,70 & 0,83 & 0,02 & 13,00 & 101,36 \\
\hline $\begin{array}{l}\text { Solo } \\
+7 \% \text { de Cal }\end{array}$ & 55,23 & 29,22 & 4,10 & 1,53 & 0,00 & 3,70 & 0,00 & 1,50 & 0,74 & 0,03 & 13,08 & 101,13 \\
\hline
\end{tabular}

* A mistura foi realizada com a amostra do solo coletado entre as profundidades de $0,80 \mathrm{~m}$ a $1,10 \mathrm{~m}$.

\subsection{Caracterização Mineralógica}

$\mathrm{Na}$ análise da TG/DTG do solo (Figura 4a) entre $100^{\circ} \mathrm{C}$ até $250^{\circ} \mathrm{C}$ há um pico endotérmico intenso de perda de água; a $400^{\circ} \mathrm{C}$, inicia-se a reação de desidroxilação do hidróxido de esmectita, que é completada a $700^{\circ} \mathrm{C}$. A Figura 4b, com os difratogramas de raios-X para o solo, indicam que há uma interestratificação irregular envolvendo minerais do tipo 2:1 como micas e minerais expansivos (esmectitas e vermiculitas), além da presença de caulinita.
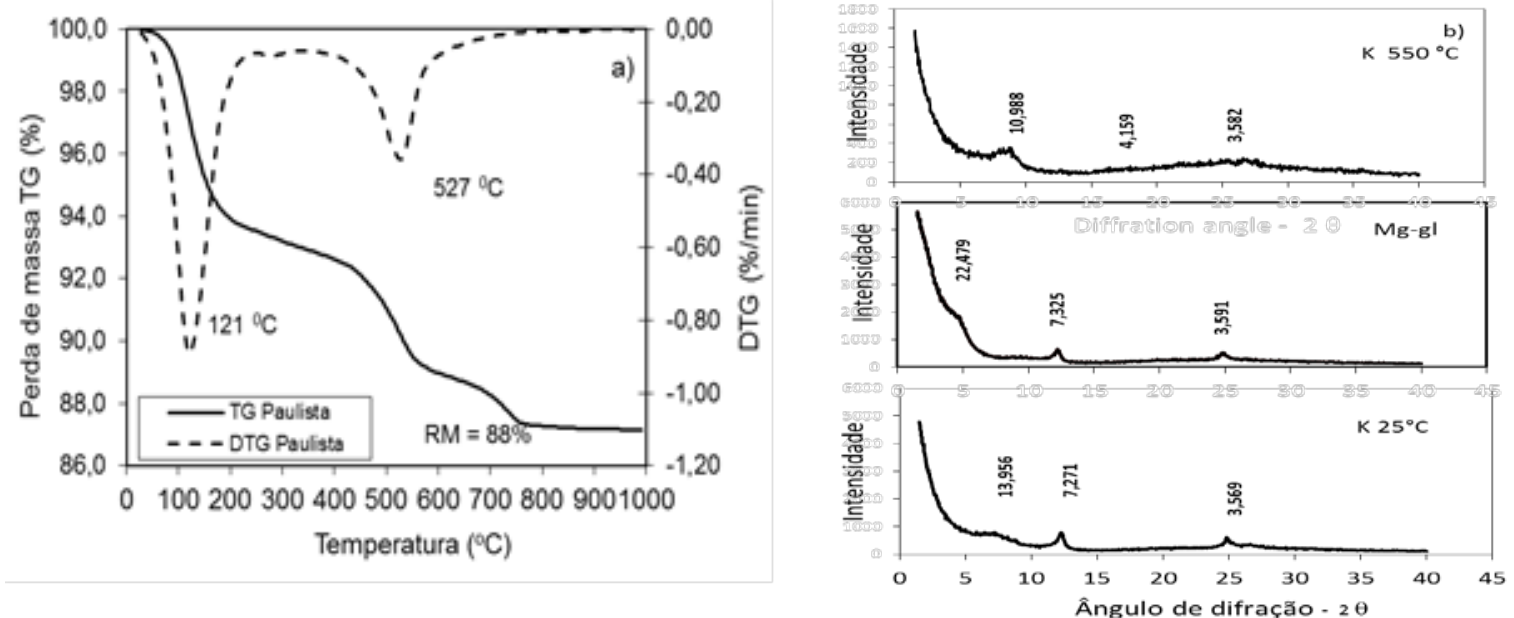

Figura 4: Curvas: a) TG e DTG, b) Difração de raio-X.

Nas curvas características dos ensaios de TG/DTG no solo acrescido de cal (Figura 5), verificam-se, nas três concentrações a perda da água na temperatura de $120^{\circ} \mathrm{C}$. Na temperatura entre 400 e $650^{\circ} \mathrm{C}$ ocorreu um pico correspondendo à perda da hidroxila do hidróxido de montmorilonita nas três concentrações de cal e na temperatura entre 650 e $750^{\circ} \mathrm{C}$ houve um pico correspondente à formação de óxido de cálcio pela decomposição da calcita. 

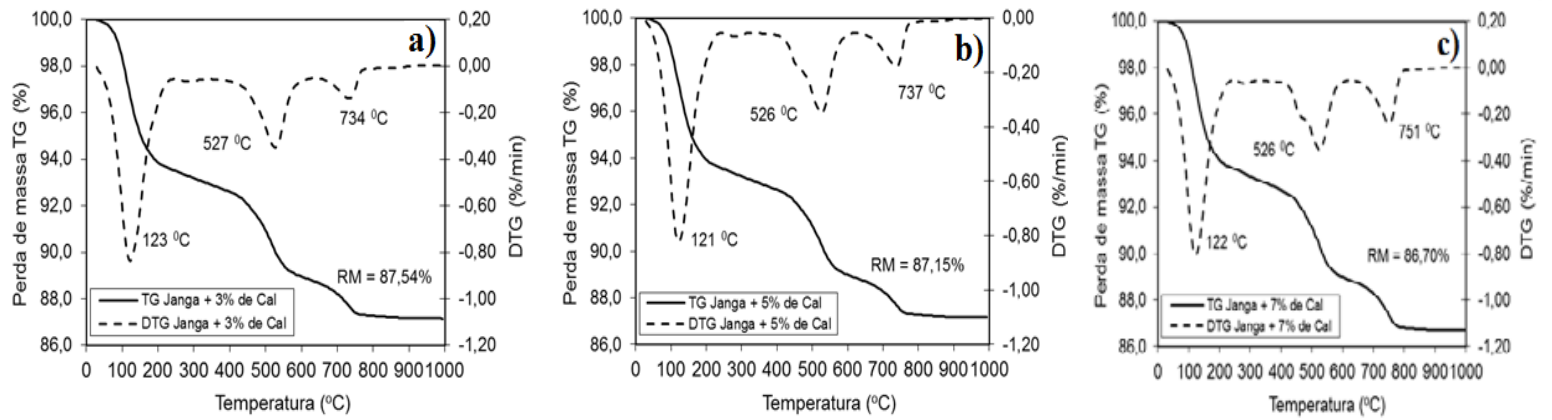

Figura 5: Curvas da TG e DTG com o correspondente do difratograma, para as misturas solo-cal: a) 3\%, b) 5\% e c) 7\%.

\subsection{Caracterização Microestrutural do Solo e das Misturas Solo-cal}

As eletron-micrografias do solo de Paulista, obtidas a partir de amostra indeformada, e das misturas do solo cal e obtidas a partir de amostras compactadas na umidade ótima e peso específico aparente seco máximo pela Microscopia Eletrônica de Varredura (MEV) estão ilustradas na Figura 6. Verificou-se no solo natural uma macroestrutura prismática formada por blocos angulares e subangulares fortes e grandes. A microestrutura é caracterizada pela união dos microagregados, composto por um plasma argiloso. A textura do solo é fina com predominância de argilas silicatadas prensadas por cristais de calcitas que compõem grande parte da fração silte e areia fina. Encontram-se pápulas (concentrações de partículas menores) por vezes lamelados, provavelmente provenientes do enchimento de canais, e poros aplanados. Há uma grande quantidade de poros aplanados, fruto da expansão e contração típicas de argilas de alta atividade; pequenas cavidades (vugh) também ocorrem, predominando as do tipo interconectado.
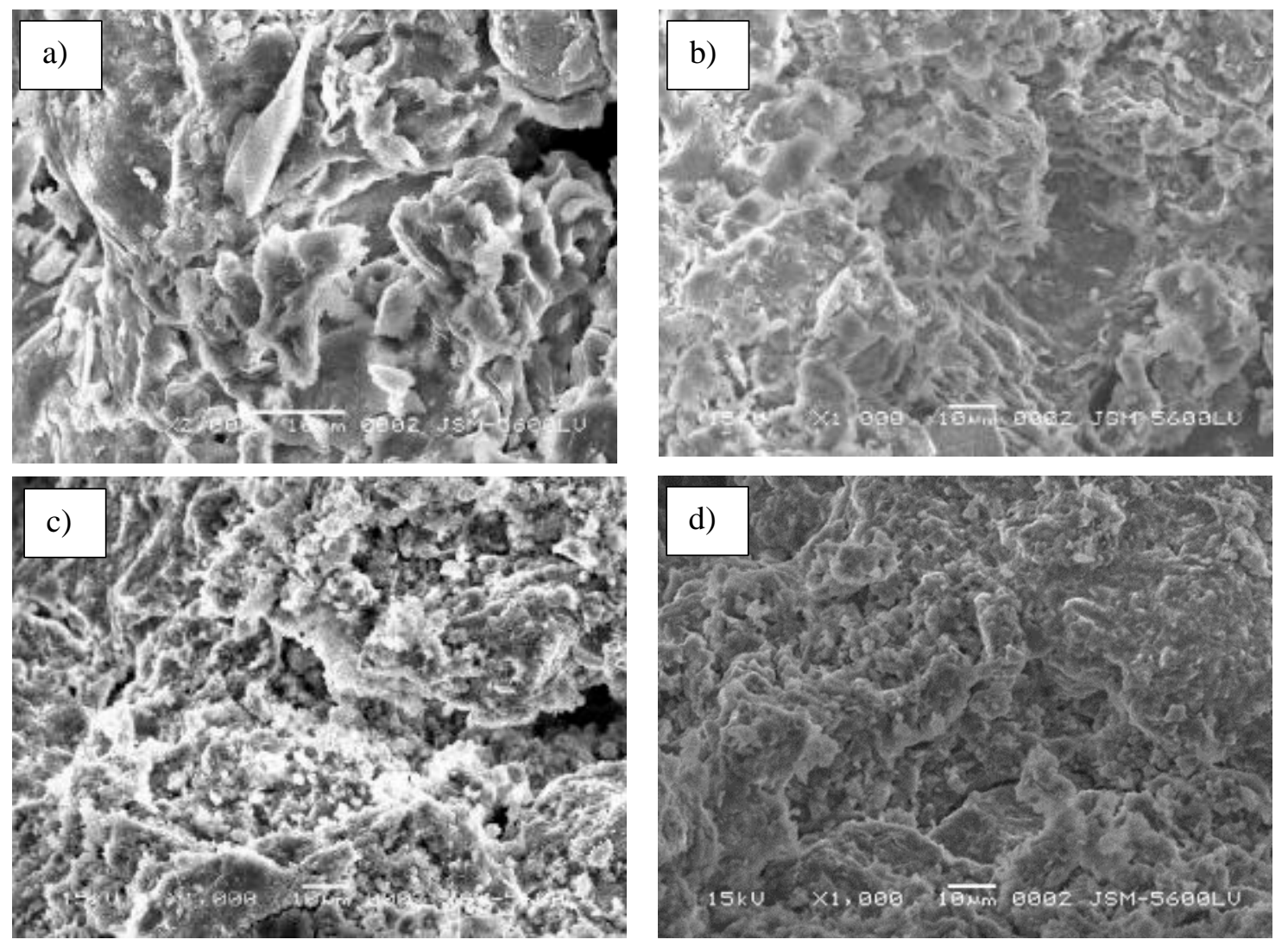

Figura 6: Eletron-micrografias a) solo de Paulista compactado, b) solo $+3 \%$ cal compactado, c) solo $+5 \%$ cal compactado d) solo $+7 \%$ cal compactado.

Verificou-se que após a adição da cal as imagens mostraram algumas alterações superficiais, quando comparadas com as amostras do solo; com o acréscimo da cal, as superfícies ficaram mais planas, com a presença de flocos resultantes das reações imediatas que a adição de cal provocaram. Com o aumento da quantidade de cal, houve alterações no tamanho das partículas argilosas em comparação com o solo sem cal. 
Indicando o início das reações da cal com a sílica presente nas estruturas dos argilominerais, e início das reações pozolânicas. Resultado também observado por SILVA [35].

\subsection{Caracterização da Expansividade do Solo e das Misturas Solo-cal}

A expansão livre calculada pela Eq 1 obtida a partir de ensaios edométricos convencionais com sobrecarga de tensão de $10 \mathrm{kPa}$ foi de 10,70\% (Figura 7). Pelo critério de Vijayvergiya e Ghazzaly [36], o grau de expansividade foi alto, e do solo de Ipojuca [37] também foi alto, Figura 8a.

Os valores da tensão de expansão do solo, determinados por diferentes trajetórias de tensões, que correspondem a diferentes métodos, são apresentados na Figura 7. O valor médio obtido pelos três métodos foi $252 \mathrm{kPa}$ (Tabela 4). A diferença fundamental entre os métodos é a ordem seguida entre a aplicação de tensão e a inundação. No Método 1, a amostra é inundada primeiro e carregada depois; no Método 2, a amostra é carregada primeiro e inundada depois; no Método 3, a inundação e carregamento ocorrem simultaneamente. As diferentes trajetórias de tensões aplicadas ao solo proporcionaram valores distintos de tensão de expansão. Comportamento similar foi obtido na argila de Petrolândia-PE por Ferreira e Ferreira [24] e por Delgado [1] na argila compactada.
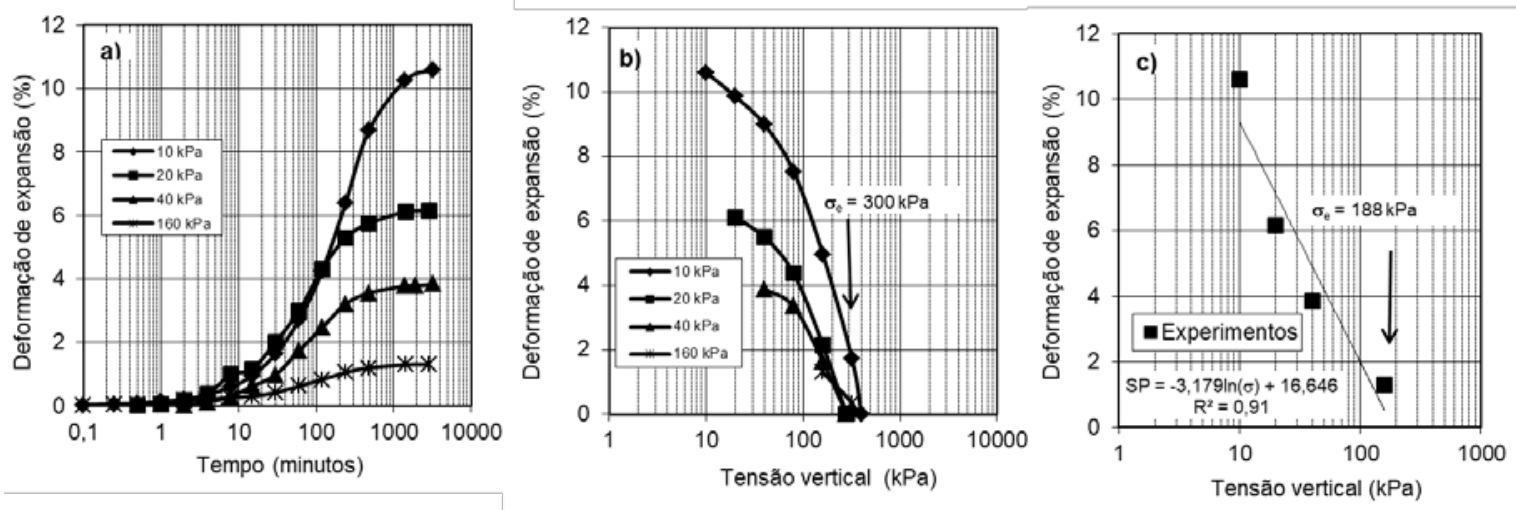

Figura 7: Métodos de tensão de expansão aplicados ao solo de Paulista: a - Expansão sob tensão; b) Método 1 Carregamento após expansão com diferentes tensões verticais de consolidação, c) Método 2 - Expansão e colapso.

Tabela 4: Tensão de Expansão

\begin{tabular}{l|c|c|c|c|c}
\hline \multirow{2}{*}{$\begin{array}{c}\text { MÉTODO DE TENSÃo } \\
\text { DE EXPANSÃo }\end{array}$} & Paulista & $\begin{array}{c}\text { Argila } \\
\text { Petrolândia } \\
{[24]}\end{array}$ & $\begin{array}{c}\text { Argila de } \\
\text { Servilha } \\
{[1]}\end{array}$ & $\begin{array}{c}\text { Argila } \\
\text { Ipojuca } \\
{[37]}\end{array}$ & $\begin{array}{c}\text { Argila de } \\
\text { Cabrobó } \\
{[40]}\end{array}$ \\
\hline $\begin{array}{l}\text { 1 Carregamento após expansão } \\
\text { com diferentes tensões verticais } \\
\text { de consolidação }\end{array}$ & 300 & 333 & 260 & 190 & 90 \\
\hline $\begin{array}{l}\text { Expansão e colapso sob } \\
\text { tensão }\end{array}$ & 188 & 239 & 150 & 220 & 100 \\
\hline 3 Volume constante & 275 & 242 & 193 & 245 & 87 \\
\hline Média & 252 & 271 & 201 & 218 & 92 \\
\hline
\end{tabular}

A adição de cal ao solo reduziu os valores da expansão "livre" (Figura 8a) e da tensão de expansão (Figura 8b) na mistura solo-cal. No solo de Paulista a adição de 5\% de cal estabilizou o solo quanto à expansão "livre" e tensão de expansão. No solo de Ipojuca a estabilização quanto à expansão "livre" e a tensão de expansão (Método a Volume Constante) foram atingidas com a adição $9 \%$ e $11 \%$ de cal respectivamente [37] e no solo de Cabrobó com adição de 3\% [38] estabilizou o solo quanto a tensão de expansão, Figura 8b. O solo expansivo natural analisado por Nalbantoglu [39] apresentou tensão de expansão de $480 \mathrm{kPa}$ e o acréscimo de 3\% de cal hidratada reduziu a tensão para $98 \mathrm{kPa}$, Figura $8 \mathrm{~b}$. O critério de Jimenez Salas [40] foi aplicado aos solos de Paulista, Ipojuca [37] e ao solo analisado por Nalbantoglu [39], Figura 8b. Observou-se que edificações construídas nesses solos podem ser demolidas e no solo de Cabrobó [38] as edificações podem apresentar fissuras importantes, Figura 8b. A adição de 3\%, 5\% e 9\% de cal respectivamente aos solos expansivos de Cabrobó [38], Paulista e Ipojuca [37] levam as edificações a não apresentarem danos, Figura 8b. 

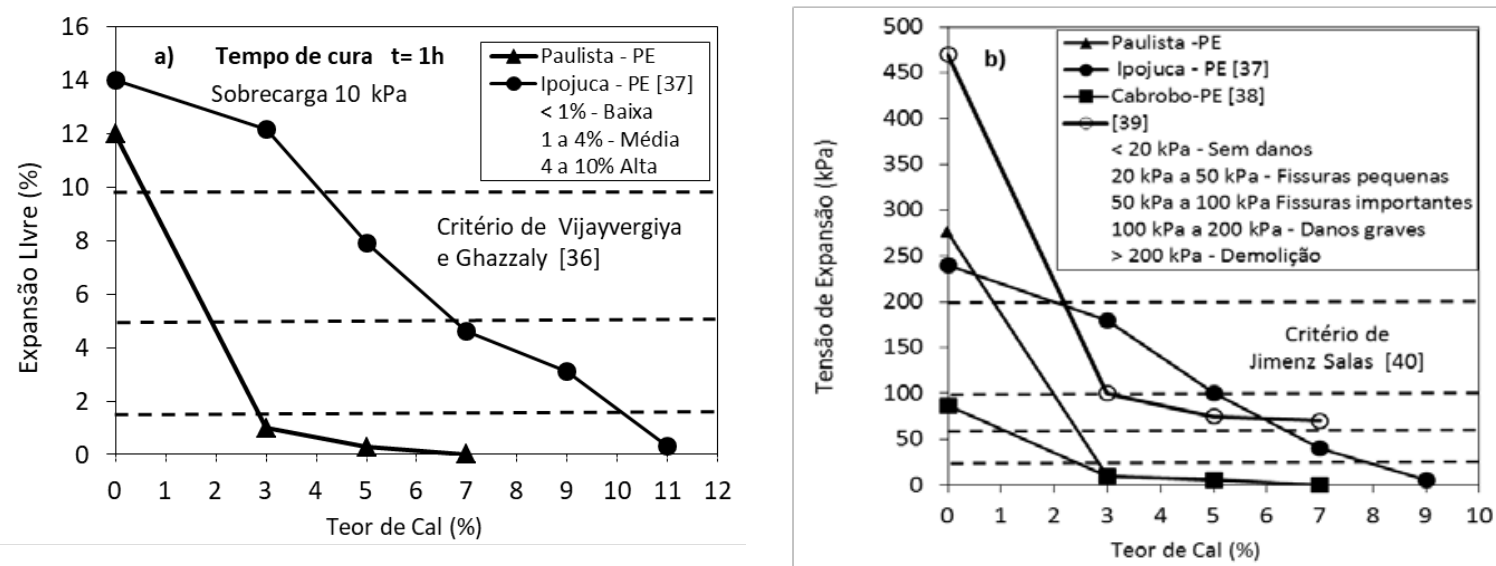

Figura 8: Expansão Livre e Tensão de expansão: a) Variação da expansão livre com o teor de cal, b) Variação da tensão de expansão com o teor de cal.

\section{CONCLUSÕES}

O solo natural de Paulista tem alta expansividade pelo critério de Vijayvergiya Ghazzaly [36], ácido (< 7) e a capacidade de troca de cátions é alta (CTC > $27 \mathrm{cmol} / \mathrm{kg}$ ). Há uma interestratificação irregular envolvendo minerais do tipo 2:1 como micas e minerais expansivos (esmectitas e vermiculitas), além da presença de caulinita. A tensão de expansão é alta podendo causar a necessidade de demolição das edificações pelo critério de Jimenez Salas [40]. O valor de 5\% de cal hidratada adicionado ao solo expansivo de Paulista reduziu a expansão livre e a tensão de expansão a valores praticamente nulos estabilizando o solo.

\section{AGRADECIMENTOS}

Ao CNPq pelo apoio na realização da pesquisa.

\section{BIBLIOGRAFIA}

[1] DELGADO, A., Influencia de la trayectoria de las tensiones en el comportamiento de las Arcillas expansivas y de los suelos colapsables en el laboratorio y en el terreno, Tesis Doctoral, Universidad de Sevillia, Espanha, 1986.

[2] JUSTO, J.L.A., DELGADO, A., RUIZ, J. "The influence of stress-path in the collapse swelling of soils at the laboratory", In: Proceedings of the International Conference on Expansive Soils, pp. 67-71, Adelaide, 1984.

[3] SIMÕES, P.R.M. "Aspectos relevantes sobre a implantação de obras de engenharia em solos e rochas expansivas”. Centro de Pesquisa e Desenvolvimento - Informe Técnico, n. 26, Camaçari - BA, 1987.

[4] FERREIRA, S.R.M., "Solos colapsíveis e expansivos: uma visão panorâmica no Brasil”, In: Simpósio Brasileiro de Solos Não Saturados, n.7, v.2, pp. 593- 619, Salvador, 2008.

[5] BOSCOV, M.E.G. Estudo comparativo do comportamento de um solo saprolítico e de um solo laterítico estabilizado com cal. Dissertação de MSc, Escola Politécnica da Universidade de São Paulo/USP, São Paulo, SP, Brasil,1990.

[6] BARBOSA, J.A., SOUZA, E.M., LIMA FILHO, M.F., et al., "A estratigrafia da Bacia Paraíba: uma reconsideração”, Estudos Geológicos, v. 13, pp. 89-108, 2003.

[7] BARBOSA, J.A., LIMA FILHO, M.F. "Aspectos estruturais e estratigráficos da faixa costeira RecifeNatal observados através de dados de poços”, Boletim de Geociências da Petrobrás, v.14, n. 2, pp, 287-305, 2006.

[8] ABNT. “ABNT/NBR 7175: cal hidratada para argamassas - requisitos”, Rio de Janeiro, 2003.

[9] ABNT. “ABNT/NBR 9290: cal hidratada para argamassas - determinação de retenção de água”, Rio de Janeiro, 1996.

[10] ABNT. “ABNT/NBR 9289: cal hidratada para argamassas - determinação da finura”, Rio de Janeiro, 1998.

[11] ABNT. “ABNT/NBR 6473: cal virgem e cal hidratada - Análise química”, Rio de Janeiro, 2003. 
[12] EADES, J.L., GRIM, R.E., A quick test to determine lime requirements for lime stabilization. In: Highway Research Record, Washington, D.C., n. 139, pp.61-72, 1966.

[13] ABNT. “ABNT/ NBR 6457: amostra de solo: preparação para ensaios de compactação e ensaios de caracterização”, Rio de Janeiro, 2016

[14] ABNT. “ABNT/ NBR 7182: solo - ensaio de compactação - procedimento”, Rio de Janeiro, 2016.

[15] ABNT. “ABNT/ NBR 6459: solo - determinação do limite de liquidez - procedimento”, Rio de Janeiro, 2016.

[16] ABNT. “ABNT/ NBR 7180: solo - determinação do limite de plasticidade - procedimento”, Rio de Janeiro, 2016.

[17] ABNT. “ABNT/ NBR 6458: solo - grãos de pedregulho retidos na peneira de 4,8 mm: determinação da massa especifica e da absorção de água”, Rio de Janeiro, 2016.

[18] ABNT. “ABNT/ NBR 7181: solo - análise granulométrica - procedimento”, Rio de Janeiro, 2016.

[19] FERREIRA, S.R.M. Colapso e expansão de solos naturais não saturados devidos à inundação, Tese de D.Sc., COPPE/UFRJ, Rio de Janeiro, RJ, Brasil, 1995.

[20] DONAGEMA, G.K., CAMPOS, D.V., CALDERANO, S.B., et al, Manual de Métodos de Análise de Solos, Rio de Janeiro, Empresa Brasileira de Pesquisa Agropecuária, Embrapa Solos, 2011.

[21] SANTOS, H.G, JACOMINE, P.K.T., ANJOS, L.H.C., et al., Sistema brasileiro de classificação de solos., 3 ed, Brasília, DF, Empresa Brasileira de Pesquisa Agropecuária, Embrapa, 2013.

[22] JACKSON, M.L. Soil chemical analysis - Advanced course, Madison, Prentice-Hall, 1979.

[23] ABNT. “ABNT/ NBR 7182: solo - ensaio de adensamento unidimensional”, Rio de Janeiro, 1990.

[24] FERREIRA, S.R.M., FERREIRA, M.G.V.X. "Mudanças de volume devido à variação do teor de umidade em um vertissolo no Semi-Árido de Pernambuco”, Revista Brasileira de Ciência do Solo, v. 33, pp. 779-791, 2009.

[25] THOMÉ, A. Estudo do comportamento de um solo tratado com cal, visando seu uso em fundações superficiai, Dissertação de MSc., Universidade Federal do Rio Grande do Sul, Porto Alegre, RS, Brasil 1994.

[26] AL-RAWAS, A.A., GOOSEN, M.F.A., Expansive soils: recent advances in characterization and treatment, London, Taylor \& Francis /Balkema, 2006.

[27] KLINSKY, L.M.G., FARIA, V.C., BERTOLLO, S.A.M., et al., “Avaliação da contribuição estrutural de subleito melhoradod com cal”, In: 42 ${ }^{a}$ Reunião Anual de Pavimentação e $16^{a}$ Encontro Nacional de Conservação Rodoviária, FAURGS, Gramado, 2013.

[28] BRANDL, H., "Alteration of soil parameters by stabilization with lime”, In: Proceedings of the International Conference on Soil Mechanics on Foundation Engeneering, 10., v.1, pp.587-595, Stockholm, 1981.

[29] SKEMPTON, A.W., "The colloidal activity of clays", In: Proceedings of the International Conference on Soil Mechanics on Foundation Engeneering, n.3. v.1, pp.587-595, London, 1953.

[30] VAN DER MERVE. "The Prediction of heave from the plasticity index and percentage clay fraction of soils”, The Civil Engeneer, South African Institute of Civil Engineers, v. 6, pp.103-107, 1964.

[31] SEED, H.B., WOODWARD, R.J., LUNDGREN, R. "Prediction of swelling potencial for compacted clays”, Journal Soil Mechanics and Foundations Division, ASCE, v. 88, pp. 53-87, 1962.

[32] DAKSANAMURTY, V. RAMAN, V. “A simple method of identifying an expansive soil”, Soils and Foundation, v.13, n. 1 pp. 97-104, 1973.

[33] YILMAZ, I. "Indirect estimation of the swelling and a new classification of soils depending on liquid limit and cation exchange capacity”, Engineering Geology, v.85, pp. 295-30, 2006.

[34] BUOL, S. W., HOLE, F. D., MCCRACKEN, F. D., et al., Soil Genesis and Classification, 4 ed., Ames, Iowa State University, 1997.

[35] SILVA. M. F., Estudo da estabilização com cal de um solo laterítico e um solo não laterítico. Dissertação de MSc., Escola de Engenharia de São Carlos/USP, São Paulo, SP, Brasil, 2016.

[36] VIJAYVERGIYA, V.N., GHAZZALY, O.I. "Prediction of Swelling Potential for Natural Clays”, In: Proceedings of the International Conference on Expansive Soils 3, v. 1, pp. 227 - 236, Hayfa, 1973.

[37] PAIVA, S.C., LIMA, M.A.A., FERREIRA, M.G.V.X., et al, Revista Matéria, v.21, n.2, pp. 437- 449, 2016. 
[38] BARBOSA, V. Estudo do comportamento geotécnico de um solo argiloso de Cabrobó, potencialmente expansivo, estabilizado com cal, Dissertação de MSc, Universidade Federal de Pernambuco, Recife, PE, Brasil, 2013.

[39] NALBANTOGLU, Z., "Lime stabilization of expansive clay”, In: AL-Rawas, A.A., Goosen, M.F.A. (eds), Expansive soils: recent advances in characterization and treatment, chapter 23, London, England, Taylor \& Francis/Balkema, 2006.

[40] JIMENEZ SALAS, J.A. “Cimentationes en terrenos expansivos o colasables”, In: Geotecnia y Cimientos III, v.1 Ed. Rueda, Madrid, pp. 533-650, 1980. 